\title{
FALHAS OBSERVADAS NO ATENDIMENTO DE DOADORES NÃO EFETIVOS E NECESSIDADES PSICOSSOCIAIS APONTADAS POR SEUS FAMILIARES: POR QUE ELES NÃO DOARAM?
}

\section{Failures observed in the care of non-effective donors and the psychosocial needs pointed out by their family members: Why did they not donate?}

\author{
Simey de Lima Lopes Rodrigues', Ilka de Fatima Santana Ferreira Boin², Helder Jose Lessa Zambelli', \\ Luiz Antônio da Costa Sardinha ${ }^{1}$, Marli Elisa Nascimento Fernandes ${ }^{3}$
}

\section{RESUMO}

Objetivo: Constatar a percepção das famílias não doadoras quanto ao atendimento recebido durante a hospitalização de seu ente querido, o doador não efetivo, bem como conhecer as necessidades dos cuidados requisitados por familiares que vivenciaram esse processo. Método: Estudo exploratório de abordagem qualitativa, tendo sido entrevistados mediante sorteio dez familiares que recusaram a doação de órgãos e tecidos no ano de 2015. Através de entrevistas semiestruturadas, foram coletados dados sociodemográficos dos familiares e relativos à experiência familiar do internamento de seus entes queridos. O material do discurso foi transcrito e submetido à análise de conteúdo temático. Resultados: Foram encontradas as categorias: insatisfação familiar com os serviços prestados nas unidades de emergência, percepção da necessidade de apoio psicológico e social manifestado pela família não doadora, necessidade de humanizar o processo de doação e sugestões apontadas pelos familiares para melhorar o processo de doação. Conclusões: Os participantes apontaram falhas no atendimento do potencial doador desde o primeiro atendimento prestado nas unidades de emergência, relacionadas à competência técnica e humanística; observou-se maior necessidade em humanizar as relações entre os profissionais de saúde e os familiares nos ambientes de cuidados intensivos, que mantiveram limitação para horário e número de visitas e no esclarecimento de informações aos familiares; constatou-se adoecimento dessas famílias e ausência de suporte socioemocional após vivenciarem esse processo. Ademais, acreditamos que práticas de atenção à saúde poderão ser discutidas, para ampliar a consciência social sobre essa temática e garantir cuidado a essas famílias, podendo contribuir para melhora dos índices de doação no Brasil.

Descritores: Morte Encefálica, Transplantes, Recusa de Participação, Obtenção de Tecidos e Órgãos, Acolhimento, Humanização da Assistência.

\section{Instituição:}

1. Organização de Procura de Órgãos - Hospital das Clínicas da Unicamp - Campinas/SP, Brasil

2. Departamento de Cirurgia da Faculdade de Ciências Médicas Universidade Estadual de Campinas - Campinas/SP, Brasil

3. Serviço Social - Hospital de Clínicas da Unicamp - Campinas/SP, Brasil

\section{Correspondência:}

Simey de Lima Lopes Rodrigues

Gastrocentro da Unicamp - Carlos Chagas, 420, Cidade Universitária Zeferino Vaz. CEP 13083-878 - Campinas/SP

(19) 3521-8582

simey.lima@gmail.com

Recebido em: 01/08/2020

Aceito em: 29/08/2020

\section{INTRODUÇÃO}

Detentor de um dos maiores programas públicos de transplantes de órgãos e tecidos do mundo, oferecendo assistência holística e gratuita, o Brasil vem se destacando em relação ao número absoluto em transplantes, ${ }^{1}$ porém ainda tem menor desempenho em relação ao número de transplantes e doadores por milhão de população, quando comparado a outros países. ${ }^{2}$

O desequilíbrio crescente entre a oferta e a demanda de órgão no Brasil1 e em países desenvolvidos ${ }^{3-5}$ pode ser minimizado se um dos caminhos mais promissores para atender essa demanda, a efetivação da doação por meio de doador falecido em morte encefálica (ME), 
Falhas observadas no atendimento de doadores não efetivos e necessidades psicossociais apontadas por seus familiares: por que eles não doaram?

que pode disponibilizar até oito órgãos por doador, além dos tecidos, for concretizada. ${ }^{6}$

Em nosso país, para se concluir a doação por meio de doador falecido, após o processo de diagnóstico da $\mathrm{ME}$, excluindo as contraindicações prévias absolutas, ${ }^{7}$ é necessária a autorização familiar assinada, validando o doador elegível em efetivo, sendo essa uma decisão difícil e complexa, levando muitos familiares a optarem pela recusa à doação, a qual se destaca como a principal causa da não efetivação nacional1 e internacional, ,3,8-11 atingindo $63 \%$ em algumas regiões brasileiras, ${ }^{1}$ retratando ser um problema multifacetado enfrentado por diversos países.

A desinformação da população e dos profissionais de saúde sobre o processo de doação de órgãos, ${ }^{12} 0$ desconhecimento familiar do desejo do parente falecido em ser doador de órgãos ${ }^{9,13}$ e a insatisfação familiar com as abordagens médicas ${ }^{9,10,12}$ foram os principais motivos que levaram os familiares ao não consentimento pela doação. Esses motivos de recusa levam-nos a reconhecer a importância da família nesse processo, assistindo às suas necessidades antes, durante e depois do diagnóstico de $\mathrm{ME}$, pois o processo de doação de órgãos depende dela. ${ }^{14}$

Considerando a complexidade do atendimento ao potencial doador (PD) e a seus familiares, faz-se necessário que os profissionais envolvidos reconheçam todas as fases e especificidades do processo de doação, tratando os familiares de forma adequada, respeitando a situação, seus sentimentos, comportamentos e sofrimentos, ${ }^{15-16}$ reduzindo $o$ estresse emocional e proporcionando um atendimento mais humanizado.

Diante da problemática, indagamos - qual a percepção das famílias de doadores não efetivos em relação ao acolhimento das equipes assistenciais? Dessa forma, traçamos o objetivo deste estudo ao constatar a percepção das famílias não doadoras do atendimento recebido durante a hospitalização de seu ente querido - o doador não efetivo, bem como conhecer as necessidades de cuidados requisitados por familiares que vivenciaram esse processo.

\section{MÉTODO}

Trata-se de estudo exploratório, de abordagem qualitativa, guiado pelas estruturas científicas COREQ 17 e SQUARE 2.0,18 a partir de dados de doadores não efetivos no ano de 2015, da Organização de Procura de Órgãos do Hospital de Clínicas da Universidade Estadual de Campinas (OPO HC-UNICAMP), coletados no período de Maio de 2016 a Dezembro de 2017.
Na Figura 1, encontra-se o fluxograma do recrutamento dos familiares deste estudo. Assim, inicialmente, constataram-se 81 casos de recusa familiar. Após atendermos os critérios de inclusão deste estudo (ser o familiar responsável pelo doador em ME e que recusou a doação de órgãos e tecidos) e de exclusão [familiares que foram entrevistados pela pesquisadora, durante 0 ano em que ela atuava na OPO $(n=8)$ e os casos com dados incompletos no prontuário que limitassem as análises realizadas $(n=41)$ ], conforme ilustra a Figura 1, 32 famílias foram selecionadas para serem entrevistadas por meio de sorteio.

Figura 1: Fluxograma do recrutamento dos familiares que recusaram a doação, na OPO HC-UNICAMP, no ano de 2015. Campinas, SP, Brasil, 2016-2017

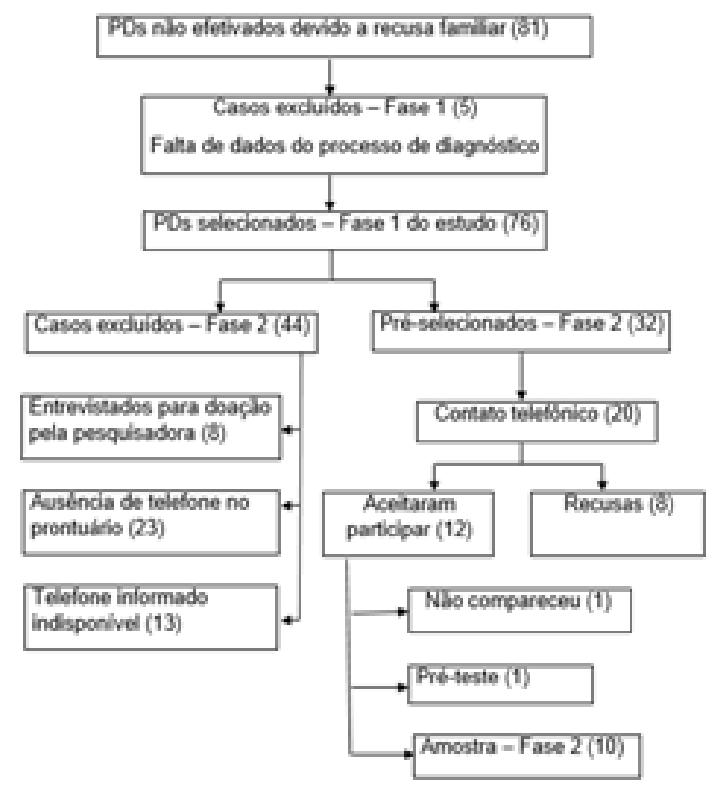

As famílias sorteadas foram contatadas por telefone e convidadas a participar de uma entrevista, agendada conforme a disponibilidade destas. Ao chegarmos à $20^{a}$ família contatada, o estudo foi interrompido por saturação das respostas (os dados obtidos passaram a apresentar uma certa redundância, sendo irrelevante realizar novas entrevistas). Destas, oito famílias recusaram participar, informando falta de condições emocionais e doze famílias disseram ter disponibilidade para participar do estudo.

A primeira entrevista foi utilizada como pré-teste, para verificar a clareza das questões e adequá-las para a condução das demais, não sendo incluída na análise do estudo; uma família não compareceu à entrevista agendada. Assim, a amostra deste estudo foi composta por dez famílias que assinaram o termo de consentimento livre e esclarecido (TCLE) e atenderam a todos os 
Simey de Lima Lopes Rodrigues, Ilka de Fatima Santana Ferreira Boin, Helder Jose Lessa Zambelli, Luiz Antônio da Costa Sardinha, Marli Elisa Nascimento Fernandes

critérios de inclusão e exclusão, sendo as entrevistas gravadas com o consentimento dos participantes para fins somente de análises dos dados.

Os familiares foram entrevistados através de questionário semiestruturado, contendo dados sociodemográficos e clínicos do doador não efetivo, como: iniciais, idade, sexo, cor da pele, estado civil, procedência, causa da $\mathrm{ME}$; dados sociodemográficos dos familiares (nome do entrevistado, relação de parentesco com o doador não efetivo, data da entrevista, sexo, escolaridade, cor da pele, estado civil, religião, vínculo empregatício, renda per capta (em salário mínimo), profissão e tempo da entrevista após a recusa para a doação (no mínimo seis meses após o óbito - em meses) e local de internação.

As questões abertas sobre a percepção dos familiares em relação ao processo de doação e das características do atendimento prestado foram: 1 . Como o(a) senhor(a) avalia as informações que foram dadas desde a suspeita da ME?; 2. Como o(a) senhor(a) avalia o atendimento dado ao seu familiar durante o tempo em que ficou no hospital internado?; e 3. O(A) senhor(a) sente a necessidade de dizer algo mais sobre esse momento de sua vida?. Apenas três entrevistas foram feitas no HC-UNICAMP, sendo as demais nos domicílios dos familiares.

As entrevistas foram transcritas na íntegra e analisadas, baseadas no referencial metodológico qualitativo da análise de conteúdo, ${ }^{19}$ sendo realizadas na pré- análise as leituras flutuantes do material coletado para identificação das categorias: insatisfação familiar com os serviços prestados nas unidades de emergências; percepção da necessidade de apoio psicológico e social manifestado pela família não doadora; necessidade de humanizar o processo de doação e sugestões apontadas pelos familiares para melhorar o processo de doação.

Respeitaram-se os aspectos éticos em todas as etapas da pesquisa, resguardando o anonimato e o sigilo dos doadores não efetivos, de seus familiares entrevistados $(F)$ e das instituições hospitalares $(H)$ de abrangência da OPO HC-UNICAMP. O estudo teve aprovação do Comitê de Ética em Pesquisa da Faculdade de Ciências Médicas da UNICAMP - CAAE: 54000316.0.0000.5404/2016.

\section{RESULTADOS}

Em relação à caracterização sociodemográfica e clínica dos doadores não efetivos arrolados neste estudo, eles estavam dentro da faixa etária de 26 a 59 anos, predominantemente pertencentes ao sexo masculino, brancos, solteiros, residentes nas Regiões Metropolitana e Administrativa de Campinas (SP), Vale do Paraíba (SP) e Microrregião de Bragança Paulista (SP), com internamento em UTI e PS, sendo o traumatismo cranioencefálico a principal causa da ME.

As informações sociodemográficas relacionadas aos familiares estão descritas na Tabela 1.

Tabela 1: Características sociodemográficas, causas da morte encefálica, unidades e tempo de internação dos potenciais doadores não efetivos do ano de 2015 da OPO HC-UNICAMP. Campinas, SP, Brasil, 2016-2017

\begin{tabular}{|c|c|c|c|c|c|c|c|c|c|c|}
\hline PD* & Idade & Sexo & Cor da Pele & Estado Civil & Procedência & Religião & Escolaridade & $\begin{array}{c}\text { Causa da } \\
\text { ME }\end{array}$ & $\begin{array}{l}\text { Unidade de } \\
\text { Internação }\end{array}$ & $\begin{array}{l}\text { Tempo de } \\
\text { Internação }\end{array}$ \\
\hline PD1 & 57 & $\mathrm{M}^{\dagger}$ & Pardo & Solteiro & Paulínia & Católica & $\mathrm{EF}^{\prime \prime}$ & AVE** & $\left.U T\right|^{\S \S}$ & 12 \\
\hline PD2 & 26 & $\mathrm{M}^{+}$ & Branca & Solteiro & Arthur Nogueira & Católica & EFII & $\mathrm{TCE}^{+\dagger}$ & UTI $\left.\right|^{\S \S}$ & 10 \\
\hline PD3 & 29 & $\mathrm{~F}^{\ddagger}$ & Branca & Solteira & Valinhos & Católica & $E M^{\uparrow}$ & $\mathrm{TCE}^{+\dagger}$ & $\left.U T\right|^{\S \S}$ & 2 \\
\hline PD4 & 29 & $\mathrm{M}+$ & Negra & Casado & Atibaia & Católica & $\mathrm{EM}^{\Uparrow}$ & $\mathrm{TCE}^{++}$ & $\left.U T\right|^{\S \S}$ & 5 \\
\hline PD5 & 59 & $\mathrm{M}+$ & Branca & Casado & Campinas & Protestante & $\mathrm{EM}^{\text {ๆ }}$ & AVE** & PSIIII & 3 \\
\hline PD6 & 56 & $\mathrm{~F}^{\ddagger}$ & Branca & Viúva & Campinas & Católica & EFII & $\mathrm{TCE}^{+\dagger}$ & PSIIII & 5 \\
\hline PD7 & 33 & $\mathrm{M}^{+}$ & Branca & Solteiro & Sumaré & Católica & $\mathrm{EF}^{\prime \prime}$ & $\mathrm{TCE}^{++}$ & PSIIII & 11 \\
\hline PD8 & 30 & $\mathrm{M}^{+}$ & Branca & Solteiro & SJC§ & Católica & $\mathrm{EF}^{\prime \prime}$ & $\mathrm{TCE}^{+\dagger}$ & $\left.U T\right|^{\S \S}$ & 5 \\
\hline PD9 & 44 & $\mathrm{~F}^{\ddagger}$ & Branca & Casada & Rio Claro & Católica & $\mathrm{EM}^{\text {ๆ }}$ & AVE** & $\left.U T\right|^{\S \S}$ & 6 \\
\hline PD10 & 49 & $\mathrm{~F}^{\ddagger}$ & Branca & Casada & Mogi-Guaçu & Evangélica & EF"I & AVE** & UT $\left.\right|^{\S \S}$ & 3 \\
\hline
\end{tabular}

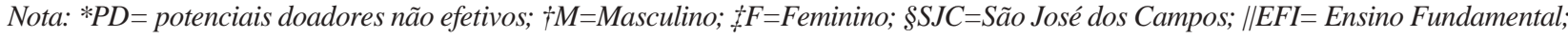

IIEM=Ensino Médio; **AVE=Acidente Vascular Encefálico; ††TCE=Traumatismo Cranioencefálico; $\$$ UTI=Unidade de Terapia Intensiva; ||||PS=Pronto-Socorro. 
Falhas observadas no atendimento de doadores não efetivos e necessidades psicossociais apontadas por seus familiares: por que eles não doaram?

Abaixo, descrevemos os achados das categorias analisadas.

Na categoria - Insatisfação familiar com os serviços prestados nas unidades de emergências, foram enfatizadas falhas no atendimento inicial prestado nas Unidades de Pronto Atendimento (UPA), como a percepção de pouca resolutividade no atendimento e assincronismo da assistência prestada com os serviços de urgência referenciados.

Evidenciou-se insatisfação familiar, tanto nas questões humanas (falha na comunicação entre os profissionais e familiares), técnicas (falta de estrutura para prestar atendimento de alta complexidade e de capacitação profissional) e administrativas (morosidade para transferência dos pacientes das UPAs aos serviços de urgência; descontinuidade da assistência, com repetição de exames; falta de informações documentais): [...] Ele já veio de um pronto atendimento, onde lá sim, houveram uma série de falhas ... ele chegou aqui, no hospital " $H$ " 8 horas depois, e o que foi entregue aqui, pelo SAMU, foi um papelzinho escrito a lápis, escrito: provável AVC. Como uma pessoa vem de um pronto atendimento, da entrada em uma emergência com um papelzinho escrito a lápis? Não tinha histórico de nada ... (F5). [...] Quando eu levei ele pro UPA, os médicos internou ele esperando uma vaga no hospital " $H$ ", só que o médico não falou $O$ que estava acontecendo, a gravidade dele ... eu não fui bem atendida porque os médicos sumiu, as enfermeiras totalmente desligadas, né, e eu achando que ele estava só com um pequeno acidente (F7). [...] Eu penso que se meu irmão tivesse sido assistido aqui no pronto socorro mais rápido, eu acho que meu irmão estaria vivo ... foi muito mal assistido, mesmo (F1).

Observaram-se falhas nas informações referentes ao atendimento inicial nos serviços de urgência referenciada (falta ou demora em obter esclarecimentos sobre a gravidade do quadro de seus entes, sendo que, algumas vezes, as informações são obtidas por meio de terceiros, e não pela equipe médica que prestou o cuidado): [...] Lá não, demorou muito, muito, muito mesmo. Assim, ninguém vinha falar nada ... O policial que foi lá entrevistar a gente pra saber o que aconteceu, né, como tinha sido... Em nenhum momento veio ninguém falar nada, ninguém, ninguém. Eu fiquei sabendo de fora por terceiros (F6). [...] Quando eu cheguei no hospital " $H$ " meu filho estava na emergência, esperando ir pra cirurgia porque deu um coágulo no cérebro. Eu passei o dia todo no hospital, ninguém vinha dar uma satisfação... Como você acha que eu estava? (F8).

$\mathrm{Na}$ percepção das necessidades de apoio psicológico e social manifestado pela família não doadora, os familiares apontaram ser importante um acompanhamento psicossocial, tanto durante quanto após a conclusão do processo de internação, pois membros da família adoeceram após vivenciarem esse processo com isolamento social e até afastamento das atividades laborais.

Algumas famílias conseguiram elaborar a perda mediante a ajuda espiritual (igreja; crença), social (amigos do trabalho) e psicológico (atendimento profissional custeados pela própria família): [...] Eu senti muita falta de um acompanhamento pós, psicológico.... Estabelecer um processo de acolhimento pós também porque fica uma coisa muito fria. Faleceu, faleceu, acabou, nunca mais ouvimos falar da instituição "H" (F5). [...] Minha irmã ficou até doente. Ela passa até hoje com psicólogo, com psiquiatra. Ela toma remédio pra dormir ... Acho que tanto durante como depois dessa fase a gente tem que ter um acompanhamento, sabe, psicológico. Minha irmã teve que afastar do serviço; ela toma remédio pra depressão (F3). [...] Pra mim ainda é muito difícil, é uma caixinha que fica guardadinha ali, né... Acho que poderia dar um suporte pra gente de psicólogo ... fiquei afastada por quase um ano do meu serviço ... tive um pouco desse suporte do pessoal do meu serviço, né (F4).

$\mathrm{Na}$ categoria - Necessidade de humanizar o processo de doação, os familiares apontaram que os profissionais precisam dar um atendimento mais humanizado. Tratase de um momento em que os parentes querem estar próximos ao ente falecido, e a presença de pessoas significativas para a família conforta-os diante da perda; apontaram dificuldades diante da limitação estabelecida pelas unidades de internamento referentes ao número de pessoas e horários de visitas.

Os familiares solicitaram que as equipes assistenciais retratassem as informações do PD a todos os membros da família e não, somente, a uma pessoa, pois além de ser um momento difícil, estão emocionalmente abalados e não conseguem transmitir as informações aos demais membros da família; além disso, apontaram que médicos e enfermeiros mantiveram uma postura totalmente fria e apática, tornando esse momento ainda mais difícil: [...] Eles não abriram nenhuma exceção, era só aquele horário e falava só comigo, pra mim falar pro resto da família ... eles podiam ser mais flexíveis ... ser mais humanos, pensar mais na família (F3). [...] Tinha algumas enfermeiras mais jovens que era uma arrogância tremenda ... Decidiu-se ali fazer uma oração, nada espalhafatoso, e essa enfermeira, simplesmente interrompeu e falou: se não entrar agora, não entra mais. Assim, não esperou 30 segundos (F5). O que mais me incomoda, o que mais, assim, é triste, né, principalmente pra mim, para os irmãos dele, é que a família quer estar presente, né ... Então assim, é um por vez ... você vai, é aquela espera, aquela agonia pro médico vim dar uma satisfação pra gente. Passa pra gente que do lado de lá, do lado deles, é um lado sem 
Simey de Lima Lopes Rodrigues, Ilka de Fatima Santana Ferreira Boin, Helder Jose Lessa Zambelli, Luiz, Antônio da Costa Sardinha, Marli Elisa Nascimento Fernandes

humanidade, né, um lado frio (F4). [...] Nós somos em 13 filhos ... você acha, todo mundo queria ver. Só entrava 2 lá na UTI, o resto ficava lá fora sofrendo ... Eu falei pro médico falar com meus irmãos e ele falou que sempre é assim, fala com um que passa as informações pra família ... mas a gente não explica direito, né (F10).

$\mathrm{Na}$ categoria - Sugestões apontadas pelos familiares para melhorar o processo de doação, os entrevistados apontaram que o sofrimento seria minimizado se, após concluído esse processo, tivessem suporte psicossocial oferecido pelo serviço público de saúde, pois o componente financeiro pode limitar o acesso a esses cuidados.

Cogitou-se que as temáticas da ME e da doação de órgãos fossem mais divulgadas para a conscientização da sociedade e solicitaram esforços para redução do tempo de doação, bem como ações no ambiente assistencial que humanizasse mais o processo de doação: [...] Tipo assim: o falecimento foi no dia primeiro, sei lá ... no dia dez, quinze, se a senhora quiser, a senhora pode voltar ... pra ver como é que está, pra conversar ... um trabalho que primeiro fosse gratuito, que é o impeditivo pra muitas pessoas ... pode ser um residente, um aluno ... enfim, mais acompanhar, dar atenção (F5). [...] Eles podiam ser mais humanos com a gente ... Acho que tem que ter mais divulgação sobre morte cerebral, sobre doação... Hoje a gente tem essas informações, mas porque a gente passou por isso (F3). [...] Se a fase da doação fosse mais rápida, com certeza nós optaríamos em doar, mas esperar tanto tempo assim, pra quem já está em sofrimento, fica muito difícil... (F6). [...] Esse é um dos únicos momentos da vida que precisamos desabafar... e tem que ser com profissional. Então, eu percebi uma dificuldade imensa para conseguir essa ajuda do postinho (F5).

\section{DISCUSSÃO}

A temática central deste estudo foi compreender as percepções das famílias de doadores não efetivos que optaram pela recusa da doação de órgãos mediante a assistência prestada durante a hospitalização de seus entes falecidos, bem como conhecer suas dificuldades e necessidades ao vivenciarem esse processo. Apesar da complexidade do assunto, entendemos que as famílias que optaram pela não doação necessitam de cuidados e ações que minimizem o sofrimento em todas suas dimensões, estruturadas pela política nacional de transplante.

Cabe ao Sistema Único de Saúde (SUS) adotar estratégias que atendam às novas demandas que se apresentam no campo da saúde, em suas múltiplas dimensões, assistencial (nesse contexto abrangendo o cuidado prestado multiprofissional, com valorização das questões técnicas e humanísticas) e social.
Estratégias locais devem ser oferecidas por profissionais da OPO, que podem despertar maior consciência social na população sobre a ME e possibilidade da doação, além de capacitar os profissionais de saúde para atenderem as demandas específicas desse processo. Apostamos que ações locais são responsáveis por mudanças significativas, em vista dos diferentes resultados referentes à doação no Brasil. ${ }^{1}$

O entendimento dos familiares relatando que houve falha técnica no atendimento do PD, durante o internamento nos serviços de emergência, pode estar demonstrando que os princípios e as diretrizes do SUS sobre resolutividade e hierarquização não estão sendo seguidos, além de possíveis erros ou equívocos diante da legislação nacional de atenção à urgência, que direciona e legaliza as ações prestadas aos usuários; 20 ou que esses familiares foram mal orientados sobre a condução de atendimento de pacientes graves. No presente estudo, os familiares associam que as falhas observadas no atendimento inicial nas UPA, se não ocorridas ou amenizadas, poderiam ser impeditivas na evolução da ME de seus entes, porém não há como prever, diante da gravidade das lesões cerebrais, a evolução clínica desses pacientes, caso o encaminhamento aos serviços de urgência fosse mais rápido.

Sabe-se que as unidades de emergência dos hospitais referenciados para casos de alta complexidade, como os pacientes com lesão neurológica graves, são caracterizadas por unidades com superlotação de pacientes, saturadas de macas pelos corredores, com estruturas físicas e de recursos humanos limitados para a demanda. ${ }^{21}$

Há uma taxa de, aproximadamente, $30 \%$ dos PD internados nas unidades de urgências, ${ }^{22}$ sendo esse, um indicador negativo no processo de doação, pois pacientes graves incluindo os PD requerem cuidados intensivos, equipe multiprofissional, orientações e esclarecimentos de todas as fases do atendimento aos familiares, e que muitas vezes, não se consegue no atendimento prestado nessas unidades.

As falhas na comunicação dos profissionais de saúde foram interpretadas pelos familiares como descaso e isso pode contribuir negativamente no decorrer da internação e durante o processo de doação, uma vez que pode induzir dúvidas e desconforto às famílias enlutadas, ${ }^{23}$ (não somente as famílias de PDs, mas todas as demais com entes internados), visto que a morte repentina de um ente provoca reações de choque e perplexidade nos familiares, comprometendo o contexto psicossocial, como as atividades cotidianas e o trabalho. ${ }^{24}$

Diante desse momento tão difícil de ser enfrentado pelos familiares, após vivenciar o processo de doação, 
Falhas observadas no atendimento de doadores não efetivos e necessidades psicossociais apontadas por seus familiares: por que eles não doaram?

os suportes emocional, social e espiritual oferecidos a eles são apontados como primordiais, amenizando - sofrimento, $^{9}$ requisitados tanto pelas famílias doadoras ${ }^{24}$ quanto por aquelas que optaram por não doar, ratificando ausência desse cuidado para as que vivenciam o processo de doação.

Considerando as sugestões apontadas pelos familiares entrevistados, os profissionais de saúde devem atentar para os núcleos familiares, encaminhando-os para participar das Práticas Integrativas e Complementares (PIC). Trata-se de uma estratégia terapêutica acessível e disponível nos serviços públicos de saúde, capaz de envolver os familiares junto à comunidade, fortalecendo laços sociais, promovendo apoio emocional, troca de experiências e diminuição do isolamento social. ${ }^{25}$

A internação de urgência de um ente gera impacto direto na dinâmica familiar e essa situação pode ser capaz de induzir um desequilíbrio emocional nos familiares. Esse momento delicado requer do médico maior compreensão das necessidades e dedicação de um tempo para a família poder assimilar os fatos que envolvem seu ente hospitalizado. ${ }^{24}$

Analisando as necessidades das famílias desse estudo, há maior demanda por atenção da equipe assistencial durante esclarecimentos do internamento e de todo processo de doação, enfatizando a empatia e profissionalismo nas relações estabelecidas, sendo essas necessidades já apontadas em outros estudos, ${ }^{9-10}$ além da demanda para flexibilizar os horários e o número de visitas, facilitando a entrada de parentes e de pessoas que as famílias julgam importantes.

Nesse sentido, os familiares sentem-se insatisfeitos por não participarem das decisões relativas ao cuidado de seu ente e pela falta de conhecimento e de esclarecimentos da equipe médica sobre o tratamento adotado e dos testes para diagnótico de ME, ficando desapontados. ${ }^{26-27}$

Os profissionais de saúde que atuam junto a pacientes críticos precisam conscientizar-se que os cuidados não se finalizam diante da morte do paciente e, quando percebem o fracasso de todas as tentativas, precisam adotar medidas e protocolos para o diagnóstico de ME; durante esse processo devem manter os familiares esclarecidos de todas as medidas adotadas, ${ }^{28}$ sendo primordial que sejam capacitados para adotarem essa continuidade do cuidado, pois há, na formação, lacunas referentes à temática da doação. ${ }^{29}$

Ademais, os familiares referem que minimizaria o sofrimento e humanizaria a assistência prestada, se ações que reduzissem o tempo para os procedimentos da extração de órgãos, que muitas vezes, contribuiram para a recusa a doação, bem como, maior divulgação das informações referentes, não somente à doação, mas também à $\mathrm{ME}$, fossem implementadas.

Durante a entrevista familiar, os profissionais que atuam na doação solicitam um tempo de 24 horas para os procedimentos necessários à extração dos órgãos e devolução do corpo do doador aos familiares para o sepultamento. ${ }^{11}$ Nesse contexto, é imprescindível a atuação dos profissionais das OPO como facilitadores do processo de doação, respeitando a legislação vigente, otimizando o tempo dos procedimentos, atuando em ações educativas com a população em geral e nos hospitais, de forma a ampliar o conhecimento sobre essa problemática, buscando estratégias para reduzir esse tempo.

Portanto, os achados desse estudo permitiram identificar as falhas de atendimento nos serviços de saúde, cabendo aos gestores a responsabilidade para concretizar ações institucionais, que beneficiarão tanto as famílias de PD quanto os demais usuários, melhorando a qualidade dos serviços prestados e ampliando o acesso aos serviços de saúde; aos profissionais da OPO, a capacitação das equipes de saúde, principalmente na habilidade para comunicar más notícias, as quais poderão ser estendidas a todas as famílias das unidades de internação.

Diante da necessidade de órgãos para transplante, é essencial que essas falhas não sejam repetidas, pois podem deixar os familiares insatisfeitos com a assistência e, consequentemente, negarem o pedido de doação.

A partir desses achados, outras práticas de atenção e gestão na saúde poderão ser discutidas, tanto no âmbito das instituições hospitalares e da rede de urgência e emergência, da educação geral da população, quanto no cuidado prestado a essas famílias, para impactar no fortalecimento dos vínculos familiares, extinguindo a ideia de abandono, da família, após o processo de doação e melhorando a consciência social sobre essa temática.

\section{CONCLUSÃO}

Este estudo revelou a necessidade de oferecer maior cuidado socioemocional aos familiares de doadores não efetivos que se sentem esquecidos e desamparados após a perda de seu ente falecido; identificou maior necessidade em humanizar as relações estabelecidas entre essas famílias e profissionais de saúde envolvidos; revelou falhas no atendimento prestado ao PD desde o momento da internação, bem como a falta de esclarecimento da população e dos profissionais de saúde quanto a ME e doação de órgãos. 
Simey de Lima Lopes Rodrigues, Ilka de Fatima Santana Ferreira Boin, Helder Jose Lessa Zambelli, Luiz Antônio da Costa Sardinha, Marli Elisa Nascimento Fernandes

\section{ABSTRACT}

Purpose: To verify the perception of non-donor families regarding the care received during the hospitalization of their loved one, the non-effective donor, as well as to know the need for care demanded by family members who experienced such process. Method: Exploratory study with a qualitative approach with ten family members who refused to donate organs and tissues interviewed in 2015. Through semi-structured interviews, sociodemographic data were collected from family members, related to the family experience of the hospitalization. The speech material was transcribed and submitted to an analysis of the thematic content. Results: The following categories were found: family dissatisfaction with the services provided in the emergency units, perception of the need for psychological and social support manifested by the non-donor family, the need to humanize the donation process and suggestions made by family members to improve the process of donation. Conclusions: Participants pointed out failures in the care of the potential donor, from the first care provided in the emergency units in relation to the technical and humanistic ability; there was a major need to humanize the relationships between health professionals and family members in intensive care environments that kept the time and number of visits constraints, and in clarifying information to family members; those families became ill and there was no socio-emotional support after experiencing this process. In addition, we believe that health care practices can be discussed to increase social awareness on this topic and to ensure the care for those families, and this can contribute to the improvement of the donation rates in Brazil.

Keywords: Brain Dead; Transplants; Refusal to Participate; Tissue and Organ Procurement; User Embracement; Humanization of Assistance.

\section{REFERÊNCIAS}

1) Brazilian Transplantation Registry. Organ Transplantation in Brazil (2010-2017). [Internet]. 2017 Jan/Dec [Cited Mar 10, 2018];23(4). Available from: http://www.abto.org.br/abtov03/Upload/file/RBT/2017/ rbt-imprensa-leitura-compressed.pdf

2) NHS Blood and Transplant. Taking organ transplantation to 2020: a detailed strategy. [Internet]. [Cited Feb 23, 2018]. Available from: http://www.nhsbt. nhs.uk/to2020/the-strategy/

3) International Registry in Organ Donation and Transplantation (IRODaT). Worldwide Actual Deceased Organ Donors 2016 (pmp). [Internet]. 2016 [Cited Dec 15, 2017]. Available from: http://www.irodat.org

4) United States of America (USA). Departament of Health \& Human Services. Organ Donation Statistics. [Internet]. 2016 Mar [cited Jan 21, 2018]. Available from: https://organdonor.gov/statistics-stories/statistics.html

5) Eurotransplant International Foundation (Eurotransplant). Statistics Report Library - Active waiting list (at year-end) in All ET, by year, by country, by organ 2018. [Internet]. 2018 [cited Feb 23, 2018]. Available from: http://statistics.eurotransplant.org/

6) United States of America (USA). Department of Health \& Human Services. Organ Donation Statistics. [Internet]. 2017 Aug [cited Feb 23, 2018]. Available from: https://organdonor.gov/statistics-stories/statistics. html\#glance
7) Westphal GA, Garcia VD, Souza RL, Franke CA, Vieira $\mathrm{KD}$, Birckholz VRZ, et al. Guidelines for the assessment and acceptance of potential brain-dead organ donors. Rev Bras Ter Intensiva. [Internet]. 2016 Feb [cited May 8, 2017;28(3):220-55. Available from: http://www. scielo.br/scielo.php?script=sci_arttext\&pid=S0103507X2016000300220. doi: 10.5935/0103-507X.20160049

8) Canadian Transplant Society (Cantransplant). Facts. [Internet]. 2014 [cited Feb 23, 2018]. Available from: http:// www.cantransplant.ca/home/

9) Groot J, Hoek M, Hoedemaekers C, Hoitsma A, Schilderman $\mathrm{H}$, Smeets $\mathrm{W}$, et al. Request for organ donation without donor registration: a qualitative study of the perspectives of bereaved relatives. BMC Medical Ethics. [Internet]. $2016 \mathrm{Jul}$ [cited Feb 25, 2018;17:38. Available from: https://bmcmedethics.biomedcentral.com/ articles/10.1186/s12910-016-0120-6. doi: https://doi. org/10.1186/s12910-016-0120-6

10) Can F, Hovardaoglu S. Organ donation: a comparison of donating and nondonating families in Turkey. Transplant Proc. [Internet]. 2017 Nov [cited Mar 25, 2018;49(9):196974. doi: 10.1016/j.transproceed.2017.09.032

11) Bahrami A, Khaleghi E,Vakilzadeh AK, Afzalaghaee $M$. Process and barriers to organ donation and causes of brain death in northeast of Iran. Electron Physician. [Internet]. 2017 Feb [cited Mar 28, 2018];9(2):3797-3802. Available from: http://www.ephysician.ir/2017/3797.pdf 
Falhas observadas no atendimento de doadores não efetivos e necessidades psicossociais apontadas por seus familiares: por que eles não doaram?

12) Teixeira RKC, Gonçalves TB, Silva JAC. Is the intention to donate organs influenced by the public's understanding of brain death? Rev Bras Ter Intensiva. [Internet]. 2012 [cited July 23, 2019;24(3):258-62. Available from: http://www. scielo.br/pdf/rbti/v24n3/en_v24n3a09.pdf doi: http://dx.doi. org/10.1590/S0103-507X2012000300009

13) Pessoa JLE, Schirmer J, Roza BA. Evaluation of the causes for family refusal to donate organs and tissue. Acta Paul Enferm. [Internet]. 2013 [cited Feb 10, 2016;26(4):32330. Available from: http://www.scielo.br/pdf/ape/v26n4/ v26n4a05.pdf. doi: http://dx.doi.org/10.1590/S010321002013000400005

14) Cinque VMC, Bianchi ERF. Stressor experienced by family members in the process of organ and tissue donation for transplant. Rev Esc Enferm USP. [Internet]. 2010 [cited Feb 19, 2016];40(4):996-1002. Available from: http://www.scielo. br/pdf/reeusp/v44n4/20.pdf. doi: http://dx.doi.org/10.1590/ S0080-62342010000400020

15) Moraes EL, Massarollo MCKB. Family refusal to donate organs and tissue for transplantation. Rev. LatinoAm. Enfermagem. [Internet]. 2008 May/Jun [cited Apr 12, 2018];16(3):458-64. Available from: http://www. scielo.br/scielo.php?script=sci_arttext\&pid=S010411692008000300020\&lng=en\&tlng=en. doi: http://dx.doi. org/10.1590/S0104-11692008000300020

16) Moraes EL, Santos MJ, Merighi MAB, Massarollo MCKB. Experience of nurses in the process of donation of organs and tissues for transplant. Rev Latino-Am Enfermagem. [Internet]. 2014 Mar/Apr [cited Jan 18, 2018;22(2):22633. Available from: http://www.scielo.br/pdf/rlae/ v22n2/0104-1169-rlae-22-02-00226.pdf. doi: 10.1590/01041169.3276.2406

17) Tong A, Sainsbury P, Craig J. Consolidated criteria for reporting qualitative research (COREQ): a 32-item checklist for interviews and focus groups. Int J Qual Health Care. [Internet]. 2007 Sept [cited Feb 18, 2016;19(6):349-57. doi: https://doi.org/10.1093/intqhc/mzm042

18) Goodman D, Ogrinc G, Davies L, Baker GR, Barnsteiner J, Foster TC, et al. Explanation and elaboration of the SQUIRE (Standards for Quality Improvement Reporting Excellence) Guidelines, V.2.0: examples of SQUIRE elements in the healthcare improvement literature. BMJ Qual Saf. [Internet]. 2016 Apr [cited Mar 20, 2017];(0):1-24. Available from: http:// qualitysafety.bmj.com/content/qhc/25/12/e7.full.pdf. doi: http://dx.doi.org/10.1136/ bmjqs-2015-004411

19) Campos CJG, Turato ER. Content analysis in studies using the clinical-qualitative method: application and perspectives. Rev. Latino-Am. Enfermagem. [Internet]. 2009 Mar/Apr [cited Feb 20, 2016;17(2):259-64. Available from: http://www.scielo. br/pdf/rlae/v17n2/pt_19.pdf. doi: http://dx.doi.org/10.1590/ S0104-11692009000200019

20) Dubeux LS, Freese E, Reis YA. Evaluation of urgent and emergency services in the hospital referral system in Northeast Brazil. Cad Saúde Pública. [Internet]. 2010 Aug [cited Mar 20, 2018;26(8):1508-18. Available from: http:// www.scielo.br/pdf/csp/v26n8/05.pdf
21) Bittencourt RJ, Hortale VA. Interventions to solve overcrowding in hospital emergency services: a systematic review. Cad. Saúde Pública. [Internet]. 2009 Jul [cited Apr 20, 2018];25(7):1439-54. Available from: http://www.scielo. br/pdf/csp/v25n7/02.pdf. doi: http://dx.doi.org/10.1590/S0102$311 \times 2009000700002$

22) Freire ILS, Vasconcelos QLDAQ, Araújo RO, Melo GSM, Costa IKF, Torres GV. Profile of potential donors by the effectiveness of donation. Rev Enferm UFSM. [Internet]. 2013 [cited Apr 20, 2018;3(Special):709-18. Available from: https://periodicos.ufsm.br/reufsm/article/view/10998/pdf. doi: $10.5902 / 2179769210998$

23) Anker AE, Akey JE, Feeley TH. Providing social support in a persuasive context: forms of social support reported by organ procurement coordinators. Health Commun. [Internet]. 2013 Feb [cited Dec 20, 2017;28(8):835-45. doi: 10.1080/10410236.2012.728468

24) Fernandes MEN, Bittencourt ZZLC, Boin IFSF. Experiencing organ donation: feelings of relatives after consent. Rev. Latino-Am Enferm. [Internet]. 2015 Sept/Oct [cited Mar 20, 2018;23(5):895-901. Available from: http://www.scielo.br/ pdf/rlae/v23n5/pt_0104-1169-rlae-23-05-00895.pdf. doi: 10.1590/0104-1169.0486.2629

25) Brasil. Ministério da Saúde. Práticas Integrativas e Complementares (PICS): quais são e para que servem. [Internet]. 2019 [Acesso em 12 de Janeiro de 2019]. Disponível em: http://www.saude.gov.br/saude-de-a-z/ praticas-integrativas-e-complementares\#politica

26) Lira GG, Pontes CM, Schirmer J, Lima LS. Family considerations about the decision to refuse organ donation. Acta Paul Enferm. [Internet]. 2012 [cited Mar 27, 2018;25(2 Special):140-5. Available from: http://www.scielo.br/pdf/ ape/v25nspe2/22.pdf. doi: http://dx.doi.org/10.1590/S010321002012000900022

27) Manuel A, Solberg S, MacDonald S. Organ Donation Experiences of Family Members. 2010. Nephrol Nurs J. [Internet]. 2010 May/Jun [cited Apr 8, 2018;37(3):229. 36. Available from: https://www.researchgate.net/ publication/45186700_Organ_donor_experiences_of_ family_members. doi: http://dx.doi.org/10.1590/S010321002012000900022

28) Martín-Escobar E. Importance of intensive care professionals for organ donation and transplantation. Rev Bras Ter Intensiva. [Internet]. 2012 [cited July 24, 2019;24(4):216-17. Available from: http://www.scielo.br/pdf/ rbti/v24n4/en_a02v24n4.pdf doi: http: //dx.doi.org/10.1590/ S0103-507X2012000400002

29) Reis FP, Gomes BHP, Pimenta LL, Etzel A. Brain death and tissue and organ transplantation: the understanding of medical students. Rev Bras Ter Intensiva. [Internet]. 2013 [cited July 24, 2019;25(4):279-83. Available from: file:///C:/ Users/Marcos/Downloads/0103-507x-rbti-25-04-0279\%20 (1).pdf doi: 10.5935/0103-507X.20130048. 